Log in | My account | Contact Us

Become a member Renew my subscription | Sign up for newsletters

$f 0 \quad G+0$

RESEARCH ARTICLES PHYSICS

\title{
Laser spectroscopy of muonic deuterium
}

Randolf Pohl1,2, ${ }^{\star}$, François Nez ${ }^{3}$, Luis M. P. Fernandes ${ }^{4}$, Fernando D. Amaro ${ }^{4}$, François Biraben ${ }^{3}$, João M. R. Cardoso ${ }^{4}$, Danie... + See all authors and affiliations

Science 12 Aug 2016:

Vol. 353, Issue 6300, pp. 669-673

DOI: $10.1126 /$ science.aaf2468

Article

Figures \& Data

Info \& Metrics

eLetters

因PDF

You are currently viewing the abstract.

\section{View Full Text}

\section{The deuteron is too small, too}

The radius of the proton has remained a point of debate ever since the spectroscopy of muonic hydrogen indicated a large discrepancy from the previously accepted value. Pohl et al. add an important clue for solving this so-called proton radius puzzle. They determined the charge radius of the deuteron, a nucleus consisting of a proton and a neutron, from the transition frequencies in muonic deuterium. Mirroring the proton radius puzzle, the radius of the deuteron was several standard deviations smaller than the value inferred from previous spectroscopic measurements of electronic deuterium. This independent discrepancy points to experimental or theoretical error or even to physics beyond the standard model.

Science, this issue p. 669

\section{Abstract}


The deuteron is the simplest compound nucleus, composed of one proton and one neutron. Deuteron properties such as the root-mean-square charge radius $r_{d}$ and the polarizability serve as important benchmarks for understanding the nuclear forces and structure. Muonic deuterium $\mu \mathrm{d}$ is the exotic atom formed by a deuteron and a negative muon $\mu^{-}$. We measured three 2S-2P transitions in $\mu \mathrm{d}$ and obtain $r_{\mathrm{d}}=2.12562(78) \mathrm{fm}$, which is 2.7 times more accurate but $7.5 \sigma$ smaller than the CODATA-2010 value $r_{\mathrm{d}}=2.1424(21) \mathrm{fm}$. The $\mu \mathrm{d}$ value is also $3.5 \sigma$ smaller than the $r_{\mathrm{d}}$ value from electronic deuterium spectroscopy. The smaller $r_{\mathrm{d}}$, when combined with the electronic isotope shift, yields a "small" proton radius $r_{p}$, similar to the one from muonic hydrogen, amplifying the proton radius puzzle.

\section{View Full Text}

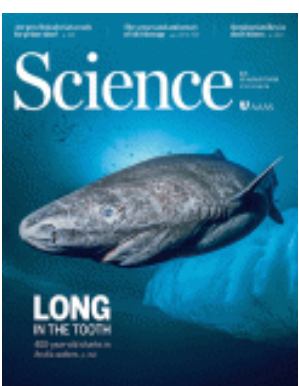

\section{Science}

Vol 353, Issue 6300

12 August 2016

Table of Contents

Print Table of Contents

Advertising (PDF)

Classified (PDF)

Masthead (PDF)

\section{ARTICLE TOOLS}

Email
Print
$\curvearrowright$ Citerts
Citation tools
خ. Download Powerpoint
Save to my folders
(C) Request Permissions
Share

Citation tools

\section{SIMILAR ARTICLES IN:}

- PubMed

- Google Scholar

\section{CITED BY...}

\section{CITING ARTICLES IN:}

- Web of Science (63)

- Scopus (67) 


\section{Related Jobs}

\section{CBG Associate II}

City of Hope

California

\section{Sr./Scientist, Delivery Sciences}

Moderna

Massachusetts

\section{Postdoc in Chemical Biology,}

\section{Metabolomics and Organic Chemistry}

SciLifeLab

Uppsala (Stad) (SE)

MORE JOBS *

\section{Science}

\section{July 2018}

Vol 361, Issue 6397

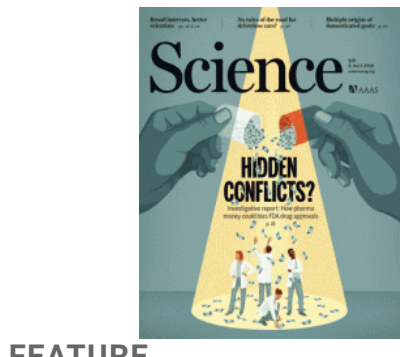

Hidden conflicts?

TECHNOLOGY DEVELOPMENT

Autonomous vehicles: No driver...no regulation?

SCIENCE \& THE ARTS

STEMM education should get "HACD"

SCI COMMUN 
News at a glance

\section{GENOMICS}

\section{America's lost dogs}

WORKING LIFE

\section{The road less traveled}

\section{Table of Contents}

\section{Subscribe Today}

Receive a year subscription to Science plus access to exclusive AAAS member resources, opportunities, and benefits.

\section{First Name}

Last Name

Email Address

\section{Subscribe Today}

\section{Get Our Newsletters}

Receive emails from Science. See full list

$\checkmark$ Science Table of Contents

$\checkmark$ Science Daily News

$\checkmark$ Science News This Week

$\checkmark$ Science Editor's Choice

$\checkmark$ First Release Notification

$\checkmark$ Science Careers Job Seeker

Country *

Email address *

I agree to receive emails from AAAS/Science and Science advertisers, including information on products, services, and special offers which may include but are not limited to news, career information, \& upcoming events.

Click to view the Privacy Policy.

\section{Sign up today}

Required fields are indicated by an asterisk (*)

\section{About us}

\section{Journals}

Leadership

Team members

Work at AAAS 
Advertise

Advertising kits

Custom publishing

\section{For subscribers}

Site license info

For members

\section{International}

\section{Chinese}

Japanese

Help

Access \& subscriptions

Order a Single Issue

Reprints \& permissions

Contact us

Accessibility

Stay Connected
f
G+
ก)

(C) 2018 American Association for the Advancement of Science. All rights reserved. AAAS is a partner of HINARI, AGORA, OARE, CHORUS, CLOCKSS, CrossRef and COUNTER. Science ISSN 1095-9203.

Terms of Service

Privacy Policy

Contact Us 